\title{
UN MATRIMONIO INTERÉTNICO eN ANDÁGUEDA (1946), DE JesÚS Botero Restrepo*
}

\author{
An interethinic marriage in $A N D A ́ G U E D A$ \\ (i 946) by Jesús Botero Restrepo \\ Juan Carlos Orrego Arismendi ${ }^{1}$
}

\begin{abstract}
* Artículo derivado de la investigación "La novela de tema indígena en Antioquia: caracterización y proceso histórico", financiada por el codi de la Vicerrectoría de Investigación de la Universidad de Antioquia en la Convocatoria Ciencias Sociales, Humanidades y Artes 2016 (código del proyecto: 2016-12871).
\end{abstract}

Cómo citar este artículo: Orrego Arismendi, J. (2021). Un matrimonio interétnico en Andágueda (1946), de Jesús Botero Restrepo. Estudios de Literatura Colombiana 48, pp. 209-223. DOI: https:// doi.org/10.17533/udea.elc.n48a13

1 https://orcid.org/0000-0002-5974-9206 juan.orrego@udea.edu.co Universidad de Antioquia, Colombia

Editores: Andrés Vergara Aguirre, Christian Benavides Martínez, Valentina Noreña Gómez

Recibido: 08.08 .2020

Aprobado: 23.10.2020

Publicado: 18.12 .2020

Copyright: (2021 Estudios de Literatura Colombiana. Este es un artículo de acceso abierto distribuido bajo los términos de la Licencia Creative Commons AtribuciónNo comercial - Compartir igual 4.0 Internacional
Resumen: En el contexto de la novela antioqueña de tema indígena, Andágueda (1946), de Jesús Botero Restrepo (1921-2008), representa un caso especial. Su trama realiza un matrimonio interétnico negado en otras novelas, y lo realiza con arreglo a la costumbre indígena, lo cual acaba de particularizarlo. Sin embargo, tras ese símbolo etnográfico se agazaparía un discurso favorable a un proyecto de mestizaje en que los elementos "blancos" y "civilizatorios" — difundidos en cruzadas como la colonización antioqueña- pretenden imponerse sobre otras expresiones étnicas, a pesar de su resistencia.

Palabras clave: Andágueda; Jesús Botero Restrepo; novela antioqueña; indios en la literatura, mestizaje.

Abstract: In the context of the Antioquian novel with an indigenous theme, Andágueda (1946), by Jesús Botero Restrepo (1921-2008), represents a special case. Its story concerns an interethnic marriage not treated in other works, and its development is in accordance with indigenous customs which in itself makes this work unique. Nevertheless, behind the ethnographic symbol, the author hides a discourse that favors a project of miscegenation in which the elements of "whites" and "civilizing" — spread through crusades such as the Antioquian colonization - tries to impose itself over ethic expression in spite of resistance.

Key words: Andágueda; Jesús Botero Restrepo; Antioquian novel; indigenous peoples in literature; miscegenation. 


\section{Introducción}

Andágueda, la primera novela del escritor antioqueño Jesús Botero Restrepo (Jardín, 1921-Medellín, 2008), fue publicada en Bogotá en 1946. ${ }^{1}$ La obra narra varios episodios de la vida de Honorio Ruiz, un arriero paisa que deja su trabajo en la mina El Torrente y se radica en una comunidad indígena del Alto Andágueda, en la selva chocoana. Allá toma como mujer a Clara Rosa Querágama y tiene un hijo con ella, pero el afán de procurarle un futuro económico a este vástago lleva a Honorio a explotar a los nativos con quienes vive, incluidos sus familiares políticos, a quienes obliga a mazamorrear oro para él. Posteriormente, abandona a su familia y prueba suerte como comerciante en el puerto de Bagadó. Cuando decide regresar, no encuentra el rastro de los indígenas y él mismo desaparece. Gracias a la narración omnisciente logra saberse cómo, muchos años después, Manuel Ruiz —el hijo de Honorio y Clara Rosa - proyecta abandonar el Chocó y "recorrer otras tierras pobladas" (Botero Restrepo, s. f., p. 204).

En el contexto de la novela de tema indígena escrita por antioqueños, la ópera prima de Botero Restrepo ocupa un lugar especial. Las dos novelas junto a las que Andágueda podría conformar la triada de las obras canónicas en ese subgénero y en esa región —Lejos del nido (1924), del rionegrero Juan José Botero (1840-1926), y Toá. Narraciones de caucherías (1933), del medellinense César Uribe Piedrahita (1896-1951) plasmaron de modo negativo el tema del enlace interétnico con expectativa de mestizaje. En Lejos del nido, Filomena Gómez, una niña blanca raptada por dos indios de El Retiro, primero rechaza de viva voz a Isidoro Quirama, el pretendiente indio con quien se pretende casarla por la fuerza, y luego, cuando el matrimonio va a celebrarse contra su voluntad, un piquete militar recluta al novio antes de entrar a la iglesia y lo arrastra al torbellino de la guerra civil. Mientras tanto, en la otra novela hay un amor correspondido entre el médico blanco Antonio de Orrantia y la mestiza carijona Nina Cuéllar - a quien Antonio llama “Toá”-, pero los últimos días de su libre unión se ven marcados por la malquerencia de las mujeres siona que los albergaban y por la muerte de Nina, desenlace en el que, de paso, se malogra el feto que la muchacha llevaba en su vientre.

La primera edición de Andágueda — a cargo de Librería y Ediciones Teoría - no indica fechas de impresión y publicación, pero la obra fue reseñada en el número de la revista Semana que circuló el 30 de diciembre de 1946 (Lleras Camargo, 1946, p. 32). En 2018, el último editor de la novela - la Universidad Eafit de Medellín- estableció 1947 como el año de su aparición original, apoyado en un artículo de John T. Reid sobre los libros hispanoamericanos aparecidos ese año (Editorial Eafit, 2018, p. 7). 
Es llamativo entonces lo que sucede en Andágueda, pues sin importar que Honorio acabe abandonando su hogar en la selva, la consumación del matrimonio con Clara Rosa es perfectamente objetiva, así como positiva en términos de la fructificación biológica que las otras novelas niegan. De hecho, ese orden de cosas no es común en la novela de tema indígena escrita en Colombia; porque, aunque Yngermina o la bija de Calamar (1844), del atlanticense Juan José Nieto - hasta donde se sabe, la primera obra de ese tipo escrita en el país-, termina con las nupcias entre Alonso de Heredia y la princesa nativa, no se refiere nada sobre su proyección en una segunda generación mestiza. Incluso en esa novela precursora la idea del mestizaje tiene un atenuante en el hecho - todo un tópico del indianismo romántico- de que Ingermina es, a su vez, mestiza; esto es, ella no representa plenamente, como símbolo literario, el factor americano. Todavía podría agregarse un argumento más sobre la singularidad de la propuesta de Andágueda, y es que el matrimonio de Honorio y Clara Rosa se concreta no bajo la forma ritual católica, sino a la usanza indígena. Fernando Ayala Poveda (1984) llamó la atención sobre ese enlace cuando, en un conocido manual, comentó la novela: "Pues bien, la historia es ingenua. Botero no sabe lo difícil que es casarse un extranjero con una indígena. Y aún más: esta relación crea una nueva modalidad. El Corín Tellado trágico a lo mestizo" (p. 287). Con todo y que la alusión del crítico raya en burla, la ponderación de lo dificultoso que resulta ese tipo de matrimonio apunta a un elemento medular en la interpretación antropológica de la novela, tal como pretendemos mostrar en este artículo.

En las páginas que siguen, ofrecemos una explicación, en clave de lectura alegórica, de ese "lugar especial" que hemos propuesto para acomodar la novela de Botero Restrepo por cuenta del matrimonio de dos de sus personajes, problema que aquí apenas hemos abordado de modo muy general.

\section{Nupcias y proyectos de integración social en la novela latinoamericana}

Doris Sommer (2004), en su trabajo sobre la novela fundacional latinoamericana, llama la atención sobre una "retórica del erotismo" o "deseo productivo heterosexual" que se impone - hasta organizarlas - en las novelas que, en diversos países del subcontinente, quisieron plasmar una imagen fundadora de sus sociedades en ciernes (p. 19). Para esta académica estadounidense, el término romance resulta doblemente apropiado para designar las novelas decimonónicas latinoamericanas 
embarcadas en ese tipo de proyectos, pues no solo alude a la narración de una "historia de amor", sino que — tal como lo consideraba la crítica de época- se distingue de otros géneros por su especial naturaleza alegórica. En ese contexto, es claro el valor simbólico del matrimonio entre los personajes de diversa condición social o extracción étnica: ellos pueden tomarse como expresión de un ideal nacional, en particular el de conseguir "consolidaciones aparentemente pacíficas durante los devastadores conflictos internos de mediados del siglo xıx"; Sommer piensa, junto con Antonio Gramsci, que el adversario social y político debe ser sometido “por medio del interés mutuo, del 'amor', más que por la coerción” (pp. 22-23). Por supuesto, suele suceder que las novelas fundacionales reflejen la negación de ese ideal, como, según reflexiona la autora, sucede en María (1867), de Jorge Isaacs, donde el matrimonio frustrado entre María, de sangre judía, y Efraín, heredero de un hacendado blanco, representaría la imposibilidad de una "amalgamación" social: la de la aristocracia con los otros, sobre todo con los negros libertos, de quienes $\mathrm{Ma}$ ría asume la representación en el discurso literario (Sommer, 2004, p. 256).

Especialmente significativas, de cara al caso que nos ocupa, son las consideraciones de Sommer sobre dos novelas en que se concreta el matrimonio de los protagonistas: Martín Rivas (1862), del chileno Alberto Blest Gana, y El Zarco (1901, póstuma), del mexicano Ignacio Manuel Altamirano. En la primera, el protagonista homónimo, hijo de un minero arruinado de provincia, logra conquistar a Leonor Encina, hija de la más rancia aristocracia santiaguina, y quien se convierte en su esposa en el desenlace de una historia agitada por la participación del novio en la rebelión liberal contra el gobierno conservador de Manuel Montt. Para Sommer (2004), el matrimonio celebra alegóricamente el acercamiento de la burguesía minera — separada de los sectores de "medio pelo", representados en la novela por Edelmira, una joven pretendiente que Martín rechaza_ y la “aristocrática’ burguesía financiera”(p. 270); la fórmula puede ser todavía más contundente: lo que Blest Gana se propone con su símbolo nupcial es "esposar el dinero con la moralidad" (p. 268). Mientras tanto, el matrimonio que tiene lugar en El Zarco entre Nicolás, un herrero indio, y Pilar — una mujer morena, de tipo no español, "sin confundirse con el indio" (Altamirano, 1984, p. 6)—, representaría el triunfo de una aspiración política de las mayorías indígenas y mestizas del país: el ascenso a la presidencia de Benito Juárez en 1861, repetido seis años después a pesar de la oposición de monárquicos europeos y criollos con simpatías europeís- 
tas — de la misma manera que en la novela, Manuela, mujer muy blanca, rechaza a Nicolás- (Sommer, 2004, p. 265); un “romance racial” que para los mexicanos y especialmente para Altamirano allanaba el camino hacia una "república indígena y liberal" (pp. 262-264). En ambos países, pues, había algo por celebrar: "algo retóricamente similar a un matrimonio dichoso" y que, a diferencia de las "fantasías" de integración social con que se confundían otros proyectos nacionales - entre ellos el colombiano-, aquí eran "hechos ya consolidados" (p. 264).

Sin embargo, el apunte más agudo de Sommer quizá consista en señalar que esos proyectos sociales materializados en Chile y México entrañaban, simultáneamente a la euforia, el riesgo de su futura debacle. Y por eso la celebración nupcial, al mismo tiempo que símbolo de lo conquistado efectivamente, se antoja como un intento igualmente figurado de conjurar el miedo de la pérdida. En Chile, cuando Blest Gana escribió Martín Rivas, los enfrentamientos entre burguesía radical y conservadores amenazaban con resquebrajar el consenso de élite del que dependía el proyecto de alianza nacional; y en México, Altamirano se había concentrado en la derrota romántica de un bandido legendario - el Zarco, arquetipo de los salteadores que asolaban al país por aquellos años - al precio de una elipsis audaz: hacer silencio en torno de la riesgosa política conciliadora de Juárez, causa de la ocupación francesa y de otras amenazas a la estabilidad social. Escribe Sommer (2004): "En la época en que los novelistas nacionales de Chile y México registraron estos triunfos, la gloria ya aparecía visiblemente empañada. Gran parte de su motivación para escribir era sin duda poder recuperar el lustre oculto bajo capas de sucesos prometedores" (p. 265). Los matrimonios de marras buscaban, pues, "aumentar la confianza ante los retos políticos" (p. 266).

No se nos pierde de vista que Sommer refiere su estudio a unas novelas cuya trascendencia social ha tenido, entre otros muchos síntomas, el que, de modo masivo, se asignen como lecturas obligatorias en la educación básica; tales son, para ella, las “novelas nacionales" (p. 20). Que Andágueda haya aparecido en un momento tardío del proceso de conformación de la nación colombiana, sumado al hecho de su circulación relativamente restringida, ${ }^{2}$ pediría reservas a la hora de extrapolar la reflexión de Sommer con el objeto de iluminar lo que se plasma en la novela. Sin embargo, es

2 En más de siete décadas se han producido cuatro ediciones de Andágueda: en 1946,1972, 1986 y 2018. Nótese que el intervalo de 14 años que media entre las ediciones segunda y tercera es el más corto de la serie. 
igualmente evidente que el imaginario de un país colombiano mestizo apenas encontró un ambiente favorable en el siglo xx, cuando los ideales modernistas, por un lado, y por otro la superación del racialismo más radical bajo el influjo de nuevos saberes científicos —una conciencia que, digamos una vez más con Sommer, era imposible en los tiempos segregacionistas de María - señalaron la oportunidad de pensar en una integración étnica. En cuanto a la otra objeción, bastará tener en cuenta que nuestro propósito no es situar a Andágueda en el canon de las novelas nacionales sino, apenas, revisar una imagen particular e inédita de sociedad nacional que, en clave alegórica, la novela de Botero Restrepo introduce en una tradición regional de novela de tema indígena.

\section{Mestizaje y resistencia: un caso colombiano}

En su trabajo de síntesis sobre la cuestión racial en Colombia durante la primera mitad del siglo xx, el antropólogo Álvaro Villegas Vélez (2006) muestra que la producción de una comunidad nacional imaginada no se identificó con un proyecto abrupto de homogeneización étnica, sino que también favoreció "importantes procesos de diferenciación" (p. 46). Por supuesto, esa diferenciación fue, parcialmente, una réplica de los discursos racialistas del siglo xIx, los cuales apelaron a criterios ambientales para clasificar los tipos humanos del país y jerarquizarlos incluso moralmente - piénsese, por ejemplo, en la idea de la supremacía del hombre andino sobre el hombre de los trópicos, defendida en los tempranos escritos científicos de Francisco José de Caldas-. Pero los intelectuales a quienes correspondió representar las nociones de raza y mestizaje en el nuevo siglo ya no pudieron ignorar los aportes de diversas disciplinas, entre ellas la antropología criminal, la antropometría y la psiquiatría (p. 48), y de ahí que su reflexión se concentrara en la idea de un mestizaje que, de manera controlada, lograra integrar a los habitantes de las tierras tropicales — sobre todo indígenas y afrodescendientes - al proyecto civilizatorio. Luis Enrique Osorio tenía claro, por ejemplo, que las zonas ecuatoriales representaban una potencia para el progreso: "Los ríos caudalosos esperan, con su poder latente, que esa raza predestinada los convierta en emporio de bienestar humano" (citado en Villegas Vélez, 2006, p. 49).

Luis López de Mesa, a pesar de sus convicciones eugenésicas a favor de un mestizaje por blanqueamiento, llegó a encontrar positivos algunos caracteres de las poblaciones amerindias. Al menos el componente caribe —en oposición al "chibcha"le parecía factor de una "recia personalidad" (citado en Villegas Vélez, 2006, p. 53), y 
de las trazas indias que sobrevivían en la conformación étnica del hombre santandereano escribió en 1934: "Es posible pensar que el elemento aborigen que entra en la composición étnica del santandereano, por discreto que sea, traiga un vigor genético determinante que se impone en la psicología de ese pueblo”(p. 54). Con todo, el más optimista de los intelectuales de época, a propósito de la potencia del factor nativo, fue el ensayista boyacense Armando Solano. Él, en la célebre conferencia que leyó en Tunja en 1927, “La melancolía de la raza indígena”, ve en el abatimiento del indio contemporáneo el producto fatal de varios factores: su sobrevivencia en medio de una naturaleza apabullante, el expolio que ha padecido históricamente y, por supuesto, su "debilidad congénita" (Solano, 1935, p. 34). Pero esa melancolía, que por un lado le confiere al indígena una especial serenidad — incluso arrojo — frente a la muerte, por otro lo dispone para la pasión, toda vez que esta solo puede existir en la aceptación del dolor y en la abnegación; de modo que, en últimas, se trata de una potencia, como claramente lo expresa el ensayista: "esa melancolía hace del tipo humano que se mueve bajo su influencia, el más apto para un progreso sustantivo e integral” (p. 28).

De modo que el pensamiento de época no desdeña algunos rasgos que el indígena puede aportar al crisol étnico nacional. Pero una vez más debe advertirse que esa intervención debía ser controlada, esto es, que lo que fuera útil en el carácter nativo debía fundirse en un tipo en que, a fin de cuentas, debían dominar los atributos del "blanco" tanto en términos de su tipo físico como de su cultura; una alternativa que Villegas Vélez (2006) sintetiza con contundencia: "la única opción... consistía en el blanqueamiento y la educación” (p. 58). En Antioquia, intelectuales como Luis López de Mesa y Fernando González valoraron el proceso de la colonización antioqueña como agente de un mestizaje positivo, pues significó la irradiación de "sangre blanca" y civilidad hacia terrenos incultos. En Los negroides (1936), González (1995) escribió puntualmente: "Si nuestros gobernantes dificultan la emigración antioqueña hacia el resto de país, permitiendo inmigración extranjera, Colombia se frustrará en cuanto a su futuro original” (p. 45). No se trata apenas de una ponderación chovinista de dos autores antioqueños: José Ramón Lanao Loaiza, intelectual caribeño, manifestó en 1920 que "El departamento más importante en Colombia ha de ser, pues, Antioquia, porque ha dado más ciudadanos a la República” (citado en Villegas Vélez, 2006, p. 65). Todavía es más significativo lo que sucedió entre las élites del Gran Cauca, las que, según Nancy Appelbaum (2007), desde mediados del siglo xIx vieron en los mi- 
grantes antioqueños la oportunidad de reocupar y con ello aprovechar, de cara a una aspiración civilizatoria, los extensos territorios que, con evidente riesgo para sus aspiraciones, eran asiento de numerosos focos indígenas y afrodescendientes. En 1857, la asamblea del Estado Soberano del Cauca conoció una solicitud de ciudadanos que apoyaban la implantación de comunidades antioqueñas, toda vez que a esos "vecinos" se les consideraba "esencialmente laboriosos, vigorosos i activos" (p. 100). Así que las élites caucanas, al mismo tiempo que asumían una imagen que los antioqueños habían promovido de sí mismos como una "sociedad regional, industrial y próspera", identificaba, como característica de su propia región, la existencia de una masa plebeya cuyos rasgos étnicos y culturales solo podían denigrarse (p. 88).

La investigación de Appelbaum deja observar que, a pesar de la aquiescencia de las élites caucanas, las expropiaciones y violencias de todo tipo desplegadas por los colonos antioqueños suscitaron una respuesta férrea y organizada en algunas parcialidades indígenas, resistencia que se extendió hasta muy avanzado el siglo xx. En efecto, en la comunidad de San Lorenzo, en Riosucio, los nativos defendieron el derecho a conservar sus tierras y trabajarlas con autonomía, además de que quisieron bloquear o retardar el mestizaje oponiéndose a los matrimonios mixtos entre las mujeres de la comunidad y los forasteros que, al casarse con ellas, aspiraban a administrar en propiedad las tierras ancestrales. Y cuando esos matrimonios indeseados se daban, las autoridades indígenas actuaban para neutralizar su efecto negativo, según escribe Appelbaum (2007):

[las autoridades del cabildo] al forzar a las mujeres indígenas que se casaban por fuera de la comunidad a renunciar a sus derechos evitaban que los maridos no indios se apoderaran de los derechos o acciones de la mujer y preservaban en forma brutal la integridad de la comunidad (p. 27I).

El antropólogo Luis Duque Gómez, al visitar San Lorenzo en 1940, se sorprendió ante la tenacidad de esa práctica endogámica (Appelbaum, 2007, p. 265). ${ }^{3}$ Sin embargo, ese mismo año, el gobierno liberal de Eduardo Santos Montejo decretó la partición de las tierras comunales indígenas, lo que problematizó no solo la autono-

De la tenacidad de la comunidad de San Lorenzo para oponerse a casar sus mujeres con foráneos da cuenta, asimismo, la novela Hildebrando (1984), del médico antioqueño Jorge Franco Vélez. El protagonista se desplaza al resguardo para llevar a cabo investigaciones parasitológicas, y una vez allí es impuesto por un colega de la desconfianza de los indígenas para integrarse con sus otros: "Le explicó que con los negros de esa vega no se podían ver, por el odio mutuo que sostenían; que a los pocos blancos del lugar los buscaban para venderles los productos de su trabajo y comprarles lo necesario para su subsistencia; del desprecio de los indios por el mestizaje" (Franco Vélez, 1996, p. 146). 
mía, sino la posibilidad misma de la existencia de los cabildos; el de San Lorenzo, por ejemplo, fue disuelto oficialmente en 1944 (p. 282). Entonces, el camino se allanó definitivamente para la ilusión del blanqueamiento y para la implantación del individualismo capitalista, impuesto por los colonos antioqueños sobre el comunitarismo ancestral.

San Lorenzo se ubica a unos 80 kilómetros lineales del escenario de Andágueda, y sus habitantes son los mismos embera-chamí que se insinúan en la novela de Jesús Botero Restrepo. Además de eso, los hechos históricos que hemos presentado sucintamente corresponden a la misma época en que el novelista conoció la región por vía de la experiencia directa y concibió su obra. Así que el emblemático matrimonio de Honorio Ruiz y Clara Rosa Querágama puede pensarse, con toda legitimidad, como símbolo de un proyecto de articulación cultural y mestizaje que cabía celebrar al mismo tiempo que sentir en riesgo. Examinaremos esa alegoría con más detalle en la siguiente sección.

\section{Matrimonio y colonización en Andágueda}

Los pocos datos biográficos con que se cuenta sobre la juventud de Jesús Botero Restrepo dan a entender que conoció de primera mano la selva del Chocó: en varias ocasiones fue hasta allá con su padre, quien se desempeñaba como funcionario del Ministerio de Correos y Telégrafos (Gómez y Gómez, 1994, p. 11); asimismo, habría abandonado sus estudios universitarios para fungir de minero en ese departamento (Mejía Vallejo, 1986, p. 2). Esto sugiere, a su vez, que entre las circunstancias de producción de Andágueda se incluyó el factor de "suficiente proximidad", reconocido por Tomás Escajadillo (1994) para el caso de la novela peruana y característico de la novela indigenista propiamente dicha, esto es, aquella que supera la perspectiva romántica que exaltó con idealismo al nativo tanto como lo ocultó bajo un discurso cristianizante (p. 42). De acuerdo con la reflexión de Roberto González Echevarría (2000), la perspectiva adoptada por Jesús Botero Restrepo correspondería a la que, al influjo de la consolidación de la ciencia antropológica, llevó un patente realismo etnográfico a la narrativa del continente (p. 38).

El matrimonio entre Honorio Ruiz y Clara Rosa Querágama es una de las evidencias más claras de la "suficiente proximidad" del novelista con la vida indígena. De acuerdo con los indicios narrativos, la mujer tiene apenas 14 años cuando es pretendi- 
da por Honorio; también logra saberse que, en la etapa del cortejo, el antiguo arriero le entrega obsequios de diversa clase, y que, una vez obtiene una respuesta positiva, él pasa a vivir "amañao" con ella, esto es, llevan una vida prenupcial a modo de prueba (Botero Restrepo, s. f., pp. 18, 75). El acuerdo definitivo con Manuel Querágama, padre de Clara Rosa, se expresa en que el novio se compromete con él para participar económicamente en la construcción de un tambo para vivir con la joven (pp. 77-78). Se trata, en esencia, de las noticias que antropólogos como Conrado Benhur Cerón Solarte y Elsa Astrid Ulloa Cubillos han ofrecido a propósito de las prácticas matrimoniales entre diversas etnias de la selva del Pacífico colombiano; de hecho, la segunda autora advierte a propósito del carácter difuso de la costumbre a fines del siglo $\mathrm{xx}$ : "ya no se practica, pues hoy en día se celebra un acuerdo sin ceremonia alguna, no se da un ritual específico sino el reconocimiento social de la pareja, el que se puede dar cuando ésta amanece unida en la casa de la joven" (Ulloa Cubillos, 1992, p. 119; véase, también, Cerón Solarte, 1992, p. 44). Así que no pueden caber dudas sobre la veracidad del dibujo etnográfico ofrecido en Andágueda, o al menos en lo que atañe a las prácticas matrimoniales.

Ahora bien, ¿qué puede significar, en la novela, la inserción de un matrimonio a la usanza indígena? Podría tratarse de una manera de expresar, en un lenguaje literario, la tesis étnica de Armando Solano: si el indígena, por su excepcional condición para el progreso, es, en potencia, un elemento favorable a la conformación de una sociedad nacional deseable, ello sugiere que él y su cultura están en la base de esa configuración y que no son su punto de llegada; porque este ha de ser un estado híbrido dominado, de todos modos, por el factor "blanco" o "civilizado". Por eso, el matrimonio de Honorio y Clara Rosa, que se celebra al modo ancestral, desemboca en el nacimiento de un niño que, de adulto, no revelará trazas indígenas: "De la sangre india que había recibido, y del carácter sombrío que le habían legado sus ascendientes, parecía carecer en realidad... Las facciones no alcanzaban a ser aindiadas"(Botero Restrepo, s. f., p. 193). El que Botero Restrepo haya bebido de las convicciones de Solano podría probarse en la manera como, en la trama, incorpora la idea de una melancolía atávica que, entre otras cosas, le permite al indio asumir con filosofía su propia destrucción. En efecto, en ocasión de haber participado Honorio en la cosecha del maíz, con sus celebraciones incluidas, la embriaguez producida por la chicha le permite acceder a una suerte de revelación sobre la concepción del destino y el tiempo de sus compañeros nativos: 
El misterioso sentido de las cosas. El secreto de la vida india como aproximación a la muerte que es descanso. El hilo del pasado y la urdimbre del porvenir. Lo vacuo de su pugna con un mundo minado por la astucia y la rapacidad. La fugacidad del tiempo en desbandada. Y la selva, tierra nueva y antigua, su nuevo mundo que pronto se iba a extinguir... Y siempre ese rito loco con que una especie cargada de años celebra su lenta destrucción, cabalgando sobre la angustia nocturna... Es el estertor de un mundo, y el clamor de una raza que rueda arrastrada por ese mundo caduco a una inmensa tiniebla (p. 89).

Una y otra vez, después de haber experimentado este rapto de "clarividencia” (p. 89), Honorio descubre en los indígenas una conducta de resignación y serenidad frente a la adversidad. ${ }^{4}$ De todos modos, también sería legítimo asumir que esa imagen del pensamiento aborigen corresponda no solo a un influjo libresco de época, sino, sobre todo, a una comprensión de la visión ancestral del mundo que apenas eclosionaba en la novela colombiana de tema indígena, y que en la literatura del continente ya acababa de dar frutos notables como Yawar Fiesta (1941), de José María Arguedas, además de que faltaba muy poco para la aparición de otra obra canónica del subgénero: Hombres de maiz (1949), de Miguel Ángel Asturias.

Una explicación alternativa para el valor simbólico del matrimonio en $A n d a ́ a-$ gueda puede obtenerse en la convergencia de la tesis estética de Doris Sommer y la reflexión histórica de Nancy Appelbaum. Si lo que hay tras las nupcias interétnicas o interclases de la literatura son celebraciones de proyectos políticos y sociales que, aunque consolidados, se creen en riesgo - y de ahí la necesidad de afirmarlos mediante el símbolo del enlace-, nada más claro que entender el matrimonio de Honorio y Clara Rosa como una celebración de la colonización antioqueña en tiempos en que ya se habían hecho evidentes sus obstáculos y problemas. Hacia el final de la primera mitad del siglo xx ya eran evidentes los resultados de la colonización en términos demográficos, económicos y de urbanización, pero, al mismo tiempo, resistencias indígenas como las de San Lorenzo habían llegado al extremo de exacerbar los ánimos del mismo gobierno central. A Botero Restrepo (s. f.), conocedor de la región, no podía escapársele la mala conciencia de la colonización —en algún pasaje de la novela, el narrador denuncia el problema de la expropiación de la tierra ancestral: velista, quien se reconoce de la misma generación que Botero Restrepo — de hecho, ambos eran oriundos de la misma subregión del suroeste antioqueño-, refiere que para ellos tenía algún valor "la prosa con tristeza nativa de Armando Solano" (Mejía Vallejo, 1986, p. 1). 
"Ellos, los indios, no. ¿A dónde podían ir que no fuesen desalojados?” (p. 153)—; y con la idea de, precisamente, anular esas amenazas fácticas y morales contra la colonización civilizatoria — no se pierda de vista que su padre había llevado el telégrafo al Chocó-, acaso vio en el símbolo nupcial la oportunidad de plasmar, en código literario, un voto de confianza sociológica en la viabilidad absoluta de la expansión de la cultura antioqueña sobre los pueblos ancestrales, autónomos culturalmente, pero uncidos a un atavismo pesimista. De hecho, si el referente inmediato de las amenazas que pesaban sobre el proyecto de expansión antioqueña era la resistencia endogámica de San Lorenzo — vigente en 1940 y sorprendente incluso para un antropólogo-, el matrimonio de Honorio y Clara Rosa viene a afirmar en la literatura lo que la realidad social niega. Quizá no haya mejor alegoría de la consumación de la colonización que esa imagen nupcial, en que el forastero blanco aparece inmiscuido en lo más profundo de un rito y un estatus reservados para los nativos. ${ }^{5} \mathrm{~A}$ la luz de esto, no parece gratuito que algunos críticos hayan visto a Andágueda como una novela sobre la colonización antes que como una novela de tema indígena propiamente dicha (Pineda Botero, 1986, p. 4; Gómez y Gómez, 1994, pp. 12-13).

$\mathrm{El}$ argumento definitivo a favor de la tesis de que el novelista, aunque reconozca la autonomía de la cultura indígena al mismo tiempo que las lacras morales de la colonización, aboga por un triunfo del proyecto "blanco" o civilizatorio reside solo parcialmente en la ya mencionada condición fenotípica de Manuel Ruiz. Hay algo más que expresa ese resultado asimétrico, manifiesto ya no solo en el predominio de un color de piel o de unos rasgos físicos —incluso de un temperamento-, sino también en un gesto distintivo, exclusivo, de incorporarse al epicentro civilizatorio. En efecto, en el último capítulo de Andágueda, Manuel y el mulato Francisco Rentería —hijo de otro colono antioqueño y una mujer negra del Chocó- viajan a "las urbes" en un autobús que conduce el segundo (Botero Restrepo, s.f., p. 199). En algún momento, para responder a una pregunta del mulato sobre la posibilidad de comercializar pieles

\footnotetext{
En la memoria de una conversación con el crítico e investigador Augusto Escobar Mesa, Manuel Mejía Vallejo refiere una noticia singular sobre la anécdota que habría dado origen a Andágueda. Cuenta el escritor de Jericó que entre los embera "no había indias putas", y que apenas se había dado, por excepción, el caso de una mujer que había huido con un blanco sin pasar por los ritos nativos del matrimonio: la hija de Manuel Querágama, "un vecino" (Escobar Mesa, 1997, p. 230). Botero Restrepo habría transformado literariamente la referencia histórica, de modo que una unión sin rito — más exactamente, una fuga- diera paso a un matrimonio a la usanza indígena cuya forzosa consecuencia no podría ser otra que la aceptación formal del blanco como pariente político del indio, con derecho a aprovecharse de su tierra.
} 
de culebra en posteriores viajes, Manuel aclara: "Ya éstos son los últimos viajes que pienso hacer, amigo Rentería. Eso de ser uno como un correo de afuera para adentro y de acá para allá, no me resulta. Voy a ver cómo me quedo por allá de un todo”(p. 207). A propósito, conviene tener en cuenta que en Cholos (1938), de Jorge Icaza - autor cuya influencia reconoció Botero Restrepo (Gómez y Gómez, 2009, p. 84)—, el cierre de la novela deja ver a blanco, indio y mestizo unidos en una causa de integración que tiene como escenario la ciudad. El que en Andágueda solo se indique ese destino para el mestizo blanqueado puede tomarse como una nítida representación de la preocupación por el control que pesaba sobre el proyecto de construcción étnica de la nación o, cuando menos, de la sociedad regional antioqueña.

\section{Conclusión}

Andágueda, a diferencia de otras novelas de tema indígena publicadas previamente en Antioquia - sobre todo de una tan segregacionista como Lejos del nido-, no cuestiona el proyecto de conformar una sociedad nacional o regional por vía del mestizaje, y en consecuencia plasma en su discurso una doble imagen afirmativa: la de Honorio Ruiz, quien participa de la cosmovisión y ritos del indio, y la de Manuel Ruiz, nacido en la mezcla biológica de india y blanco. Por supuesto, ello no impide que esa concepción del mestizaje se piense de modo asimétrico, toda vez que abarca una lógica de blanqueamiento racial, así como la consigna de no permanecer en la cultura y, en general, en el ámbito de la vida indígena: el símbolo de un matrimonio interétnico entre Clara Rosa Querágama y Honorio, efectuado bajo la costumbre nativa pero fructificado en un hijo casi blanco que viaja a la ciudad, es expresión nítida de ese orden de cosas. También puede decirse, con una perspectiva histórica y regional más particularizada, que esa representación nupcial y reproductiva funge como reafirmación, en el plano literario, de un proyecto de mestizaje y "civilización” como la colonización antioqueña, el cual, al mismo tiempo que no podía esconder sus propias fisuras morales - por lo menos ya no podía hacerlo hacia mediados del siglo $\mathrm{xx}$-, tampoco podía correr el riesgo de no concretar su expansión a causa de resistencias indígenas locales.

Vuelta a considerar la diferencia, enunciada en la introducción, que mediaría entre Andágueda y una novela temprana como Yngermina o la bija de Calamar, habría que decir que esa diferencia no se reduce al sello cultural de un matrimonio. Sobre 
todo, se trata de las maneras de representar, en la alegoría literaria, distintas concepciones de mestizaje y, también, distintas circunstancias de riesgo en la aspiración de constituir, por esa vía, una sociedad nacional. En el siglo xIX se tiene la visión de que lo indio quedó relegado en un pasado lejano - tanto, que incluso una evocación histórica es incapaz de recuperar una india "pura"-, y por eso el tipo de mestizaje que constituyó la nación es visto como un proyecto consumado y a salvo de amenazas: una india que ha dejado de serlo puede tomar parte, igual que si fuera española, en un modus vivendi occidental y cristiano. Pero en la primera mitad del siglo xx, cuando un nuevo momento intelectual obliga a repensar el proyecto y a incluir al indígena como uno de sus elementos constitutivos - así se tratara de un elemento que debía ser transformado radicalmente- - la necesidad de llevar el mestizaje por la senda adecuada — de controlarlo — obliga a afirmar las imágenes deseadas, y por eso no del todo acabadas, en el discurso literario. La india debe casarse con el blanco y hacerlo en el territorio nativo y bajo las costumbres que imperan allí: de esa manera se neutraliza, en el plano simbólico, uno de los riesgos históricos del proyecto del mestizaje; en el caso concreto de las comunidades embera-chamí cercanas al Alto Andágueda, el que los indígenas no quisieran poner sus tierras ancestrales a disposición de los colonos antioqueños. En pocas palabras, la amenaza que Andágueda quiere neutralizar es la del aborigen que, a pesar de situarse en una posición adversa, apuesta por un proyecto de autonomía étnica.

\section{Referencias bibliográficas}

Altamirano, I. M. (1984). El Zarco. La Navidad en las montañas. Ciudad de México: Porrúa.

Appelbaum, N. (2007). Dos plazas y una nación: razas y colonización en Riosucio, Caldas 1846-1948. Bogotá: Instituto Colombiano de Antropología e Historia (Icanh), Universidad de Los Andes, Universidad del Rosario.

Ayala Poveda, F. (1984) Manual de literatura colombiana. Bogotá: Educar Editores.

Botero Restrepo, J. (s. f.). Andágueda. Bogotá: Librería y Ediciones Teoría.

Cerón Solarte, C. (1992). Grupo Awa-cuaiquer. En A. Chaves Mendoza (Coord.). Geografía humana de Colombia. Región del Pacifico (pp. 9-62). Bogotá: Instituto Colombiano de Cultura Hispánica.

Editorial Eafit (2018). Nota editorial. En J. Botero Restrepo. Andágueda (1947). Café Exasperación (1963) (pp. 7-8). Medellín: Editorial Eafit.

Escajadillo, T. (1994). La narrativa indigenista peruana. Lima: Amaru Editores. 
Escobar Mesa, A. (1997). Érase un viento... y en ese viento mi alarido: Memoria compartida con Manuel Mejía Vallejo. Medellín: Biblioteca Pública Piloto.

Franco Vélez, J. (1996). Hildebrando. Medellín: Universidad de Antioquia.

Gómez, M. L. y Gómez, S. (1994). Jesús Botero Restrepo y la búsqueda del perdón. El Colombiano Dominical (1 de mayo), pp. 11-16.

Gómez, M. L. y Gómez, S. (2009). Entrevista a Jesús Botero Restrepo por Martha Luz Gómez y Sophía Gómez. En: J. Botero Restrepo. El tiempo se ha quedado solo. Cuentos y poemas (pp. 73-86). Medellín: Editorial Eafit.

González, F. (1995). Los negroides. Ensayo sobre la Gran Colombia. Medellín: Universidad Pontificia Bolivariana.

González Echeverría, R. (2000). Mito y archivo. Una teoría de la narrativa latinoamericana. Ciudad de México: Fondo de Cultura Económica.

Lleras Camargo, A. (atribuido) (1946). Las cuatro eses. Semana 10, p. 32.

Mejía Vallejo, M. (1986). Prólogo. En J. Botero Restrepo. Andágueda y Café Exasperación (pp. 1-6). Medellín: Departamento de Antioquia.

Pineda Botero, A. (1986). Andágueda: ¿novela indigenista? El Colombiano Dominical (26 de octubre), p. 4.

Solano, A. (1935) Prosas. Bogotá: Minerva.

Sommer, D. (2004). Ficciones fundacionales. Las novelas nacionales de América Latina. Ciudad de México: Fondo de Cultura Económica.

Ulloa Cubillos, E. A. (1992). Grupo indígena los emberá. En A. Chaves Mendoza (Coord.). Geografía bumana de Colombia. Región del Pacifico (pp. 93-131). Bogotá: Instituto Colombiano de Cultura Hispánica.

Villegas Vélez, A. (2006). La élite intelectual colombiana y la nación imaginada: raza, territorio y diversidad (1904-1940). Anuario de Historia Regional y de las Fronteras 11, pp. 45-71. 